UDC 316.334 .23

LBC 60.561

\title{
DEVELOPMENT PROSPECTS OF NON-PROFIT ORGANIZATIONS AS SUPPLIERS OF SOCIAL SERVICES: ON THE EXAMPLE OF THE VOLGOGRAD REGION ${ }^{1}$
}

\author{
Maria B. Poltavskaya \\ Volgograd State University, Volgograd, Russian Federation \\ Elena O. Danilova \\ Volgograd State University, Volgograd, Russian Federation \\ Elena V. Abashkina \\ Volgograd State University, Volgograd, Russian Federation; \\ Social Protection Committee of the Population of the Volgograd Region, \\ Volgograd, Russian Federation
}

\begin{abstract}
The article provides an analysis of the formation of the social services market in the Volgograd region since the adoption of a federal law that introduced fundamental changes in the field of social services, allowing non-profit organizations to act as full participants in the social services market. A review of domestic publications addressing key issues is presented: economic and managerial aspects of access of non-profit sector organizations to the social services market, infrastructure support, the formation of a state support system, successful regional practices. The role of non-governmental suppliers in the social services market is shown, the specifics of the modern institutional structure of the social services market are described. The current state of the social services market is characterized, the data of the report of the Ministry of Economic Development of Russia for 2018 on the implementation by the constituent entities of the Russian Federation of measures to ensure access to non-profit organizations to budgetary funds are presented. The main quantitative indicators of the social services market of the Volgograd region are highlighted. The results of a sociological study showed that the majority of the population does not use the services of non-profit organizations, the popularity of their services is low, and free services are most in demand. The possibilities of non-profit $\underset{\sim}{\sim}$ organizations when entering the social services market of the Volgograd region were identified: extensive

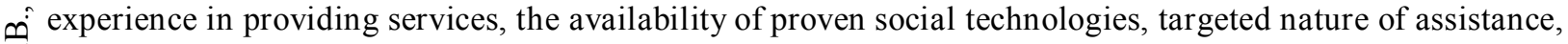
tis customer focus. Despite the creation of conditions for expanding the access of non-governmental organizations to budget financing, there are barriers to accessing the social services market: delayed cost recovery when services are completed, economically unjustified tariffs, insufficient compensation to non-state suppliers, unnecessarily bureaucratic reporting procedure of non-profit organizations for services provided. To develop the demand and supply of non-profit organizations, it is necessary to inform the beneficiaries in more detail about the quality of the services provided, tariffs, increase the level of public confidence, introduce successful experience in other regions. Creating favorable social and economic conditions, consolidating the efforts of all interested parties can create an effective system of social services in the Volgograd region on the principles of interagency cooperation.
\end{abstract}

Key words: non-profit organizations, social services, social services market, social services providers, innovative technologies, social services, social protection of the population. 
УДК 316.334 .23

ББК 60.561

\title{
ПЕРСПЕКТИВЫ РАЗВИТИЯ НЕКОММЕРЧЕСКИХ ОРГАНИЗАЦИЙ КАК ПОСТАВЩИКОВ СОЦИАЛЬНЫХ УСЛУГ: НА ПРИМЕРЕ ВОЛГОГРАДСКОЙ ОБЛАСТИ ${ }^{1}$
}

\author{
Мария Борисовна Полтавская \\ Волгоградский государственный университет, г. Волгоград, Российская Федерация \\ Елена Олеговна Данилова \\ Волгоградский государственный университет, г. Волгоград, Российская Федерация \\ Елена Викторовна Абашкина \\ Волгоградский государственный университет, г. Волгоград, Российская Федерация; \\ Комитет социальной защиты населения Волгоградской области, г. Волгоград, Российская Федерация
}

\begin{abstract}
Аннотация. В статье приводится анализ становления рынка социальных услуг в Волгоградской области с момента принятия федерального закона, внесшего принципиальные изменения в сфере социального обслуживания населения, разрешив некоммерческим организациям выступать полноправными участниками рынка социальных услуг. Представлен обзор отечественных публикаций, затрагивающих такие ключевые вопросы, как: экономические и управленческие аспекты доступа организаций некоммерческого сектора на рынок социальных услуг, инфраструктурная поддержка, формирование системы государственной поддержки, успешные региональные практики. Показана роль негосударственных поставщиков на рынке социальных услуг, описана специфика современной институциональной структуры рынка социальных услуг. Охарактеризовано современное состояние рынка социальных услуг, приведены данные отчета Минэкономразвития России за 2018 г. о реализации субъектами РФ мер по обеспечению доступа некоммерческим организациям к бюджетным средствам. Выделены основные количественные показатели рынка социальных услуг Волгоградской области. Результаты социологического исследования показали, что большинство населения не пользуются услугами некоммерческих организаций, наиболее востребованы бесплатные услуги. Выявлены возможности некоммерческих организаций при выходе на рынок социальных услуг Волгоградской области: большой опыт оказания услуг, наличие апробированных социальных технологий, адресность помощи, ориентированость на клиента. Несмотря на формирование условий для расширения доступа негосударственных организаций к бюджетному финансированию, имеются барьеры доступа к рынку социальных услуг: задержка возмещения затрат по завершении оказания услуг, экономически необоснованные тарифы, недостаточные размеры компенсаций негосударственным поставщикам, излишне бюрократизированная процедура отчетности СО НКО за оказанные услуги. Для развития спроса и предложения некоммерческих организаций следует более детально информировать благополучателей о качестве предоставляемых услуг, тарифах, повышать уровень доверия населения, внедрять успешный опыт других регионов. Создание выгодных социально-экономических условий и консолидация усилий всех заинтересованных сторон способствуют созданию в Волгоградской области эффективной системы социального обслуживания на принципах межведомственного взаимодействия.

Ключевые слова: некоммерческие организации, социальные услуги, рынок социальных услуг, поставщики социальных услуг, инновационные технологии, социальное обслуживание, социальная защита населения.
\end{abstract}

\section{Введение}

Социальное благополучие и уровень счастья населения во многом зависят от качества и доступности предоставляемых социальных услуг. Несколько лет назад в РФ стар- товала реформа социального обслуживания, ключевая цель которой заключается в снижении расходов государства в социальной сфере за счет предоставления негосударственным поставщикам социальных услуг доступа к рынку социальных услуг. С 2014 г. вступил в 
силу Федеральный закон «Об основах социального обслуживания граждан в Российской Федерации», содержащий принципиальные изменения в сфере социального обслуживания населения: некоммерческим организациям было дано право выступать поставщиками социальных услуг, закреплено новое понятие «получателей социальных услуг». До принятия закона в сфере социального обслуживания в России присутствовало не более $1 \%$ частных поставщиков социальных услуг, включая малый и средний бизнес, некоммерческие организации и отдельных граждан, действующих через НКО [Доклад... 2015, 65]. С принятием вышеназванного закона стартовал процесс передачи некоммерческим организациям части федеральных функций по оказанию социальных услуг населению, в регионах стала складываться практика межсекторного партнерства в совместном решении социальных проблем. С 2016 г. государство активно привлекает социально ориентированные некоммерческие организации (СО НКО) на рынок социальных услуг, разработав дорожную карту [Дорожная карта... web].

Руководствуясь требованиями законодательства, большинство некоммерческих организаций созданы для решения тех задач, с которыми повседневно имеют дело государственные и муниципальные органы. Это забота о малообеспеченных, социально неблагополучных гражданах, лицах с ограниченными возможностями здоровья, содействие воспитанию и образованию детей и подростков, сохранение и развитие культуры, реальная защита прав и свобод, гарантированных Конституцией, и многое другое из того, что не может быть обеспечено только на коммерческой, рыночной основе.

\section{Обзор публикаций}

Реформирование сферы социального обслуживания в России активно обсуждается научным сообществом. За последние несколько лет опубликовано значительное количество исследований, посвященных различным аспектам развития и расширения рынка социальных услуг. Экономические и управленческие аспекты доступа организаций некоммерческого сектора на рынок социальных услуг описаны в работах российских ученых [Косыгина 2017; Рудник, Куштанина, Романова 2017; Самойлова 2018].

Вопросы создания инфраструктуры, нацеленной на помощь СО НКО, выстраивания государственной системы поддержки раскрыты в трудах отечественных авторов [Белокрылова, Вахтина 2017; Борисова, Полищук 2009; Громова, Мерсиянова 2016; Кулькова 2019; Протасеня 2017; Справится ли государство... 2012].

Проблемы оценки эффективности и результативности деятельности СО НКО на рынке социальных услуг поднимаются в ряде исследований [Богуславская, Боброва 2016; Оценка... 2018; Корнеева 2017; Корнеева, Ойнер 2018].

Социологический ракурс проблематики освоения некоммерческим сектором рынка социальных услуг представлен работами, которые посвящены вопросам взаимодействия органов власти и некоммерческих организаций, преимуществам и слабым сторонам субъектов взаимодействия [Земляк, Лапшова, Шеломенцева 2016; Мерсиянова, Беневоленский 2016; Мерсиянова, Беневоленский 2017; Московская 2018; Шевченко, Захаров 2016; Salamon, Benevolenski, Jakobson 2015; Krasnopolskaya, Skokova, Pape 2015].

Региональные практики выхода СО НКО на рынок социальных услуг описаны в публикациях авторов [Артамонова 2018; Заболотная, Ларионов 2017; Николенко, Серова 2017; Палибина и др. 2017; Суслова 2014].

\section{Современное состояние рынка социальных услуг: федеральный и региональный уровни}

Специфику любого рынка, его структуру, состав основных участников, особенности взаимоотношений, складывающихся между ними, а также правила регулирования процессов в ходе функционирования - в первую очередь определяет благо. Для рынка социальных услуг таким благом выступают социальные услуги и их результат, проявляющийся в уровне удовлетворения потребностей и определяемый в широком смысле как уровень жизни населения. Социальные услуги являются квазиобщественными благами, поскольку они подвержены прямому государственному регулированию, государство со- 
знательно берет на себя затраты на их производство, предотвращая возникновение дефицита и распространяя на них принцип исключения.

Специфика современной институциональной структуры рынка социальных услуг возрастание роли некоммерческих организаций. Некоммерческие организации как производители социальных услуг выступают полноправными участниками рынка социальных услуг, предоставление социальных услуг на платной основе обусловливает включение некоммерческих организаций в конкурентные взаимоотношения с другими производителями услуг.

В условиях поиска оптимальных вариантов развития института социального обслуживания особую актуальность получает внедрение в эту сферу рыночных механизмов. Создание в российских регионах управляемого рынка социальных услуг призвано повысить качество социального обслуживания населения и обеспечить широкий спектр предоставляемых услуг в соответствии с запросами потребителей. Социальное обслуживание населения преимущественно осуществляется за счет ресурсов региональных бюджетов и в основе имеет принципы адресности и нуждаемости.

Несмотря на осознание и понимание государственными структурами роли организаций некоммерческого сектора, в том числе и в сфере социального обслуживания, использование его потенциала на сегодняшний момент недостаточно. В России на 2014 г. насчитывались 7202 государственные организации социального обслуживания, из них негосударственных только 78. Государственные организации за год оказали услуги 26 млн человек, а негосударственные - 27 тыс. человек. Согласно дорожной карте Минтруда РФ участие некоммерческих организаций в оказании социальных услуг населению в 2014 г. оценивалось в 1,2 \% [Приказ... 2014]. Организации некоммерческого сектора являются партнерами государственных структур в социальном обслуживании населения, независимо от готовности последних отдавать на освоение некоммерческим организациям достаточно ограниченный круг услуг - социально-бытовых, социально-психологических и социально-правовых.
Согласно отчету Минэкономразвития России за 2018 г. о реализации субъектами РФ мер по обеспечению СО НКО поэтапного доступа к бюджетным средствам, выделяемым на предоставление социальных услуг населению, общий объем средств, переданных субъектами РФ СО НКО на предоставление населению услуг в социальной сфере, составил более 31,3 млрд рублей. Эти средства были распределены между 4,4 тыс. СО НКО, услуги которых получили более 22 млн человек. Лидерами по количеству СО НКО, предоставляющих услуги населению в сфере социальной защиты и социального сопровождения, по итогам 2018 г. являются: Республика Татарстан (96 СО НКО), г. Москва (83 СО НКО), Республика Башкортостан (60 СО НКО), г. Санкт-Петербург (53 СО НКО), Брянская область (45 CO НКО) [Отчет... web]. Однако статистические данные отчета Минэкономразвития не позволяют полноценно охарактеризовать ситуацию в сфере доступа СО НКО на рынок социальных услуг. Общественная палата РФ подготовила специальный доклад «Участие НКО в оказании услуг в социальной сфере» с целью описания реального положения дел СО НКО при освоении рынка социальных услуг [Участие... 2019].

В доклад включены данные мониторинга отдельных отраслей социальной сферы, описаны лучшие региональные практики и зарубежный опыт по привлечению поставщиков на рынок социальных услуг. Выделены барьеры доступа к рынку социальных услуг для СО НКО: низкие тарифы, не позволяющие выйти на уровень рентабельности; межведомственный характер услуг; долговременные (до года) задержки с бюджетными выплатами за уже оказанные услуги; избыточная отчетность, отсутствие цифровизации в этой области и др.

Волгоградская область активно включилась в процесс передачи рынка социальных услуг некоммерческим организациям, утвердив в 2013 г. региональную программу «Государственная поддержка социально ориентированных некоммерческих организаций, осуществляющих деятельность на территории Волгоградской области» на 2014-2020 гг. с целью увеличения объема и повышения качества услуг.

В Волгоградской области в 2015 г. был создан реестр поставщиков социальных услуг. 
В 2016 г. в реестр входили 6 СО НКО, в 2017 г. - 14 СО НКО, в 2018 г. - 27 СО НКО. По состоянию на 21 октября 2019 г. в Волгоградской области поставщиками социальных услуг являются $25 \mathrm{CO}$ НКО по следующим направлениям деятельности: социальное обслуживание на дому; услуги в полустационарной форме для лиц без определенного места жительства и занятий; оказание реабилитационных услуг для детей-инвалидов; социальная поддержка детей и семей, которые признаны нуждающимися; социальная поддержка несовершеннолетних и лиц из числа детей-сирот и детей, оставшихся без попечения родителей; социальная поддержка детей-инвалидов, детей, испытывающих трудности в социальной адаптации, и их родителей и (или) законных представителей; услуги в стационарной форме социального обслуживания гражданам пожилого возраста и инвалидам, частично или полностью утратившим способность к самообслуживанию.

Численность получателей социальных услуг у негосударственных поставщиков увеличилась в 2017 г. (3 585 человек) в 16,3 раза по сравнению с 2016 г. (220 человек). Количество предоставленных социальных услуг в 2017 г. составило 845056 , что в 28,2 раза больше по сравнению с 2016 г. (29 997 социальных услуг). В плане мероприятий дорожной карты «Повышение эффективности и качества услуг в сфере социального обслуживания населения Волгоградской области на 2013-2018 годы» в 2017 г. плановое значение показателя «Удельный вес граждан пожилого возраста и инвалидов (взрослых и детей), получивших услуги в СО НКО, в общей численности граждан пожилого возраста и инвалидов (взрослых и детей), получивших услуги в организациях социального обслуживания всех форм собственности» составлял $4 \%$, фактически было достигнуто 8,8 \% (количество пожилых граждан и инвалидов, включая детей-инвалидов, обслуженных некоммерческими организациями, составило 3573 человека, общее количество граждан указанной категории - 40606 человек) [Постановление... web].

С целью расширения доступа некоммерческих организаций, осуществляющих деятельность в социальной сфере, к бюд- жетным средствам, выделяемым на предоставление социальных услуг, используются различные механизмы государственного финансирования $\mathrm{HKO}$ - поставщиков услуг в социальной сфере: бюджетные субсидии, выделяемые на конкурсной основе, бюджетные субсидии, выделяемые на внеконкурсной основе по постановлению органа исполнительной власти; бюджетные субсидии на возмещение затрат, госзакупки, потребительский сертификат; налоговые льготы НКО [Участие... 2019, 72].

В Волгоградской области предоставляется субсидия на возмещение поставщикам социальных услуг, включенным в реестр поставщиков социальных услуг Волгоградской области, но не участвующим в выполнении государственного задания (заказа), недополученных доходов, возникающих в результате предоставления социальных услуг гражданину - получателю социальных услуг. В 2015 г. размер компенсации составил 143,9 тыс. руб., в 2016 г. - 3 707,7 тыс. руб., в 2017 г. 11 369,4 тыс. руб., в 2018 г. - 29 691,4 тыс. рублей. В 2015 г. в рамках компенсации негосударственными организациями было обслужено 20 получателей социальных услуг, предоставлено 3842 социальные услуги, тогда как в 2018 г. уже было обслужено 824 получателя социальных услуг, предоставлено 348684 социальные услуги. Для СО НКО Волгоградской области предусмотрены также субсидии на конкурсной основе, доступна система закупки для государственных и муниципальных нужд (государственный заказ).

Несмотря на принятые меры поддержки некоммерческого сектора, направленные на расширение участия негосударственного сектора экономики в оказании социальных услуг, формирование условий для расширения доступа негосударственных организаций к бюджетному финансированию со стороны государства, некоммерческие организации Волгоградской области не спешат осваивать рынок социальных услуг.

По сравнению с регионами - лидерами по количеству СО НКО, работающих на рынке социальных услуг (Республика Татарстан, г. Москва, Республика Башкортостан, г. СанктПетербург, Брянская область), в Волгоградской области таких организаций меньше в два- 
М.Б. Полтавская, Е.О. Данилова, Е.В. Абашкина. Перспективы развития некоммерческих организаций

три раза. Чтобы определить существующие преимущества и барьеры для некоммерческих организаций при выходе на рынок услуг социального обеспечения, охарактеризовать осведомленность населения региона о негосударственных организациях - поставщиках социальных услуг, выявить отношение к процессу разгосударствления социальных услуг, а также систематизировать возможности и барьеры СО НКО при выходе на рынок социальных услуг Волгоградской области, нами было проведено социологическое исследование.

\section{Результаты исследования}

Метод исследования - массовое формализованное интервью $(N=655$, возраст от 18 лет и старше, март-апрель 2018 г.). Выборка стратифицированная, квотная, репрезентирующая половозрастной состав внутригородских районов г. Волгограда.

Было выявлено, что большинство населения г. Волгограда не пользуется услугами $\mathrm{CO} \mathrm{HКО} \mathrm{-} \mathrm{таковых} \mathrm{по} \mathrm{данным} \mathrm{исследования}$ $70,5 \%$ (табл. 1).
Только 17,9 \% респондентов сказали, что пользовались услугами некоммерческих организаций. Таким образом, популярность услуг, оказываемых СО НКО, среди жителей г. Волгограда невысока.

По-прежнему востребованы бесплатные услуги, именно такой вид услуг выбрало большинство респондентов - 52,1 \% (табл. 2).

О том, что использовали платные услуги, заявили $10,3 \%$ респондентов, льготными услугами воспользовались 27,3 \% опрошенных. Смешанным видом услуг (платные или бесплатные) воспользовались 10,3 \%. Таким образом, бесплатные социальные услуги занимают примерно половину объема предоставляемых услуг, вторую половину составляют услуги, оказываемые за плату, в том числе частичную.

Что касается характеристики услуг в плане объема их предоставления, то большинство респондентов указало, что они были оказаны в полном объеме (57,3 \%) (табл. 3). Еще 37,6 \% респондентов выбрали вариант «Скорее да, чем нет». Можно отметить, что подавляющее большинство опрошенных (95\%)

Таблица 1

Распределение ответов на вопрос: «Пользовались ли Вы социальными услугами, предоставляемыми некоммерческими организациями?»

\begin{tabular}{|l|c|c|}
\hline \multicolumn{1}{|c|}{ Ответ } & Частота & $\%$ \\
\hline Да, пользовался такими услугами & 117 & 17,9 \\
\hline Нет, не пользовался & 462 & 70,5 \\
\hline Затрудняюсь ответить & 76 & 11,6 \\
\hline \multicolumn{1}{|c|}{ Всего, чел. } & 655 & 100 \\
\hline
\end{tabular}

Таблииа 2

Распределение ответов на вопрос: «Эти услуги были платными или бесплатными?»

\begin{tabular}{|c|c|c|}
\hline Ответ & Частота & $\%$ \\
\hline Платные & 12 & 10,3 \\
\hline Бесплатные & 61 & 52,1 \\
\hline Частично платные (льготные) & 32 & 27,3 \\
\hline Некоторые платные, некоторые бесплатные & 12 & 10,3 \\
\hline Всего, чел. & 117 & 100 \\
\hline
\end{tabular}

Таблица 3

Распределение ответов на вопрос: «Эти услуги были оказаны в полном объеме?»

\begin{tabular}{|l|c|c|}
\hline \multicolumn{1}{|c|}{ Ответ } & Частота & $\%$ \\
\hline Да & 67 & 57,3 \\
\hline Скорее да, чем нет & 44 & 37,6 \\
\hline Скорее нет, чем да & 4 & 3,4 \\
\hline Нет & 2 & 1,7 \\
\hline \multicolumn{1}{|r|}{ Всего, чел. } & 117 & 100 \\
\hline
\end{tabular}


заявили, что услуги им были оказаны в полном или почти полном объеме. О неполном и частично полном объеме заявили только 5,1 \% респондентов.

Ответы на следующий вопрос характеризуют отношение респондентов к предоставлению СО НКО платных социальных услуг (табл. 4).

Однозначноподдерживают предоставление платных социальных услуг 36,3 \% респондентов (сумма ответов «Да» и «Скорее да, чем нет»). Респондентов, которые не поддерживают предоставление платных социальных услуг (сумма ответов «Нет» и «Скорее нет, чем да»), больше $-47,8 \%$. Еще $16 \%$ затруднились с ответом. Таким образом, жители г. Волгограда в 2018 г. были не готовы к получению платных социальных услуг, поскольку в течение длительного времени получали их на безвозмездной основе.

Чтобы охарактеризовать преимущества и барьеры СО НКО при выходе на рынок социальных услуг, в 2018 г. нами были проведены глубинные интервью с экспертами, имеющими опыт межсекторного взаимодействия $(N=25)$.

Некоммерческие организации более гибки и обладают способностью быстрее реагировать на изменения в предпочтениях благополучателей, оказывать услуги адресно: «Mbl быстро подстраиваемся под наших клиентов. Хотят они, чтобы мы им не только оказали типичную для всех услугу, стриж$к y$, например, а еще и приехали на дом, ик этой услуге добавили сопутствующие. Мbl сможем это сделать, а госучреждения вряд ли» (Эксперт 3, ж., 36 лет).

Имеют некоммерческие организации за плечами большой опыт оказания услуг, свои уникальные социальные технологии, которые ими давно апробированы, что свидетельству- ет о возможности СО НКО предоставлять нетипичные социальные услуги: «Мы работаем на рынке сочиильных услуг давно. О нас многие знают, недостатка в клиентах у нас нет, наоборот, очередь, по записи работаем. Есть у нас в иентре специалисты по восстановлению речи, да и вообще специалисты с большой буквы. Они и с детками проблемными работают, у которых серьезные проблемы с речью, и взросльх после болезни восстанавливают. Того же инсульта, например. Так к таким специиалистам очередь, из других регионов едут, к ним попасть хотят» (Эксперт 5, ж., 47 лет).

Таким образом, способность быстро подстраиваться под потребности клиентов, наличие уникальных социальных технологий, опыта предоставления нетипичных социальных услуг являются преимуществами СО НКО.

Руководители СО НКО говорили о барьерах, с которыми они столкнулись при вхождении в реестр поставщиков социальных услуг: «Это было восемь месячев ада, пока мы вставали в реестр. Восемь раз нам возвращали документы из Минюста. Mы отправляем документы, в Москве зачеркивают одно слово и возврашают. И так восемь раз. Вот скажите, кто готов столько времени потратить на это? (Эксперт 7, ж., 39 лет).

Вспоминали также о низких тарифах на социальные услуги, о непрозрачном механизме их установления, из-за чего оказывать их невыгодно: «Есть у меня знакомые в соседнем регионе. Так они ту же самую услугу продают в два раза дороже, чем у нас тут» (Эксперт 9, ж., 43 года).

Еще одной проблемой выступает временной лаг - задержка с компенсацией, бюджетными выплатами за уже оказанные услуги:

Таблица 4

Распределение ответов на вопрос: «Вы поддерживаете предоставление некоммерческими организациями платных социальных услуг?»

\begin{tabular}{|c|c|c|}
\hline Ответ & Частота & $\%$ \\
\hline Да & 84 & 12,8 \\
\hline Скорее да, чем нет & 154 & 23,5 \\
\hline Скорее нет, чем да & 136 & 20,8 \\
\hline Нет & 176 & 26,9 \\
\hline Затрудняюсь ответить & 105 & 16 \\
\hline Всего, чел. & 655 & 100 \\
\hline
\end{tabular}


«Порядок такой: изначально мы оказываем услуги пожильм получателям социальных услуг, и потом есть определенные прочедуры сдачи документов по оказанным услугам, проверки этих документов и ожидание денег. И вот здесь самое интересное: денег нет. А сколько мы вот так вот без денег протянем? А если бы было полное финансирование, как это и должно было быть, тогда тема прекрасная» (Эксперт 16, ж., 45 лет).

Среди положительных моментов и сильных сторон своих СО НКО, которые помогают им осваивать рынок социальных услуг, руководители называли наработанный с годами опыт, знание потребностей своих клиентов, разработку собственных уникальных услуг и технологий: «Bот у нас услуги есть, их никто больше не оказывает. В государственных организачиях все стандартизировано, они не могут от строгого регламента отойти, если у них такая услуга не прописана. А мы можем ее быстро оформить и оказывать» (Эксперт 21, ж., 52 года).

Данные нашего исследования подтвердили тенденции, характерные для СО НКО, работающих на рынке социальных услуг в других регионах РФ. Полученные данные не противоречат основным выводам доклада Общественной палаты РФ и позволяют выделить возможности и описать основные барьеры для СО НКО при выходе на рынок социальных услуг Волгоградской области.

\section{Выводы}

Таким образом, на территории Волгоградской области используются все механизмы бюджетного финансирования СО НКО. Формируется новый рынок социальных услуг, происходит процесс диверсификации услуг, трансформируются функции некоммерческих организаций. Модернизация и оптимизация системы социального обслуживания населения нацелена на пересмотр механизмов и способов предоставления социальных услуг, организацию социального партнерства и межсекторного взаимодействия, создание конкурентоспособной среды за счет расширения реестра поставщиков социальных услуг.
Согласно данным Центра исследований гражданского общества и некоммерческого сектора НИУ ВШЭ, прослеживается тенденция увеличения числа информированных граждан об институтах гражданского общества и повышается степень их доверия. Однако получатели социальных услуг все еще отдают предпочтение государственным органам социального обслуживания [Волонтерство... web]. Данные нашего исследования подтвердили эту тенденцию: большинство опрошенных не пользуется услугами СО НКО, по-прежнему востребованы бесплатные услуги, многие неготовы к получению платных социальных услуг, поскольку в течение длительного времени получали их на безвозмездной основе. Таким образом, без сложившегося доверия населения некоммерческим организациям, формирования их позитивного имиджа и известности платные социальные услуги СО НКО среди населения Волгоградской области будут оставаться невостребованными.

СО НКО Волгоградской области обладают сильными сторонами и возможностями, благоприятствующими при выходе на рынок социальных услуг: большой опыт оказания социальных услуг, наличие уникального набора услуг и апробированных социальных технологий, адресность и индивидуальность оказываемой помощи, ориентированость на клиента. Среди барьеров доступа СО НКО к рынку социальных услуг Волгоградской области можно назвать проблему временных лагов (задержка возмещения затрат по завершении оказания услуг), экономически необоснованные тарифы, недостаточные размеры компенсаций негосударственным поставщикам, излишне бюрократизированная процедура отчетности СО НКО за оказанные услуги.

Для развития спроса и предложения некоммерческих организаций следует более детально информировать благополучателей о качестве предоставляемых услуг и реальных тарифах, повышать уровень доверия населения и квалификацию сотрудников, внедрять успешный опыт других регионов. Формирование выгодных социально-экономических условий, консолидация усилий всех заинтересованных сторон содействуют созданию в Волгоградской области эффективной системы социального обслуживания на принципах межведомственного взаимодействия. 


\section{ПРИМЕЧАНИЕ}

${ }^{1}$ Работа выполнена в рамках научного проекта № 17-13-34010 «Ресурсный потенциал некоммерческих организаций в сфере социального предпринимательства» при финансовой поддержке РФФИ и Администрации Волгоградской области.

The study was carried out with the financial support of the RFBR and the Administration of the Volgograd region, project no. 17-13-34010 "Resource potential of non-profit organizations in social entrepreneurship".

\section{СПИСОК ЛИТЕРАТУРЫ}

Артамонова 2018 - Артамонова А.С. Функционирование социально ориентированных некоммерческих организаций в российских регионах // Проблемы развития территории. 2018. № 5 (97). С. 55-67.

Белокрылова, Вахтина 2017 - Белокрылова О.С., Вахтина М.A. Обеспечение доступа субъектов рынка социальных услуг к госзаказу: проблемы и решения // Государственное и муниципальное управление. Ученые записки СКАГС. 2017. № 1. С. 78-84.

Богуславская, Боброва 2016 - Богуславская С.Б., Боброва О.С. Оценка эффективности проектов некоммерческих организаций, социального предпринимательства и гражданских инициатив. СПб.: Изд-во Политехн. ун-та, 2016.

Борисова, Полищук 2009 - Борисова Е.И., Полищук Л. И. Анализ эффективности в некоммерческом секторе: проблемы и решения // Экономический журнал Высшей школы экономики. 2009. № 13 (1). С. 80-100.

Волонтерство... web - Волонтерство и участие россиян в деятельности НКО и гражданских инициатив // Центр исследований гражданского общества и некоммерческого сектора // https:/ /grans.hse.ru/06_04_2017 (дата обращения: 23.09.2019).

Громова, Мерсиянова 2016 - Громова М.Н., Мерсиянова И.В. Государственная поддержка НКО и проблема оценки ее эффективности // Гражданское общество в России и за рубежом. 2016. № 1. С. 44-47.

Доклад... 2015 - Доклад о состоянии гражданского общества в Российской Федерации за 2015 год. М.: Общественная палата Российской Федерации, 2015.

Дорожная карта... web - Дорожная карта «Поддержка доступа негосударственных организаций к предоставлению услуг в социальной сфеpe»// http://economy.gov.ru/minec/activity/ sections/socorientnoncomorg/2016291104 (дата обращения: 23.09.2019).

Заболотная, Ларионов 2017 - Заболотная Г.М., Ларионов A.B. Региональные практики институционализации негосударственных поставщиков социальных услуг // Вопросы государственного и муниципального управления. 2017. № 3. С. 72-91.

Земляк, Лапшова, Шеломенцева 2016 - Земляк C.B., Лапшова О.А., Шеломенщева М.В. Взаимодействие региональной власти с общественными некоммерческими организациями // Экономика. Налоги. Право. 2016. № 5. С. 105-112.

Корнеева 2017 - Корнеева И.Е. Ориентация на рынок в некоммерческом секторе: сущность концепции и основные направления исследований // Вестник Санкт-Петербургского университета. Менеджмент. 2017. Т. 16, № 4. C. 564-595.

Корнеева, Ойнер 2018 - Корнеева И.Е., Ойнер О.К. Ориентация на рынок и результативность деятельности российских некоммерческих организаций // Вестник Санкт-Петербургского университета. Менеджмент. 2018. № 17 (4). С. $437-464$.

Косыгина web - Косыгина К.Е. Место некоммерческого сектора в региональной экономической системе [Вопросы территориального развития. 2017. № 4 (39)] // http://vtr.isert-ran.ru/ article/2360 (дата обращения: 23.09.2019).

Кулькова 2019 - Кулькова В.Ю. Организация инфраструктурной поддержки социально ориентированных некоммерческих организаций сферы услуг в государственном управлении в РФ // Вопросы управления. 2019. № 2 (38). С. $58-65$.

Мерсиянова, Беневоленский 2016 - Мерсиянова И.В., Беневоленский В.Б. Преимущества НКО как поставщиков социальных услуг: апробация в российских условиях // Вопросы государственного и муниципального управления. 2016. № 4. C. 7-26.

Мерсиянова, Беневоленский 2017 - Мерсиянова И.В., Беневоленский В.Б. НКО как поставщики социальных услуг: верификация слабых сторон // Вопросы государственного и муниципального управления. 2017. № 2. С. 83-104.

Московская 2018 - Московская А.А. Стимулы и барьеры привлечения негосударственных поставщиков к оказанию социальных услуг: российский и зарубежный опыт // Вопросы государственного и муниципального управления. 2018. № 3. С. 88-116.

Николенко, Серова 2017 - Николенко Н.А., Серова Я.И. Государственный сектор и СО НКО в сфере социальной защиты населения: парт- 
неры или конкуренты? // Вестник Удмуртского университета. Социология. Политология. Международные отношения. 2017. Вып. 2. C. $162-166$.

Отчет... web - Отчет о реализации субъектами Российской Федерации мер по обеспечению доступа социально ориентированных некоммерческих организаций к предоставлению услуг в социальной сфере в 2018 г. // http:// nko.economy.gov.ru/portalnews/read/4967 (дата обращения: 23.09.2019).

Оценка... 2018 - Оценка экономической и социальной эффективности добровольческой деятельности: методические подходы и проблемы реализации / под ред. И.В. Мерсияновой. М.: НИУ ВШЭ, 2018.

Палибина и др. 2017 - Палибина А.С., Панькова Е.Г., Соловьева Т.В., Бистяйкина Д.А. Некоммерческие организации в системе социального обслуживания населения // Дискуссия. 2017. № 10 (84). C. 55-59.

Постановление... web - Постановление Правительства Волгоградской области от 26.03.2013 № 128-п «Об утверждении плана мероприятий (“дорожной карты”) "Повышение эффективности и качества услуг в сфере социального обслуживания населения Волгоградской области" на 2013-2018 годы»// http:// www.consultant.ru/law/review/reg/rlawc/ rlawc1262013 (дата обращения: 23.09.2019).

Приказ... - Приказ Минтруда России от 30.04.2014 № 282 (ред. от 13.04.2016) «О плане мероприятий (“дорожной карте”) “Повышение эффективности и качества услуг в сфере социального обслуживания населения" (20132018 годы)»// http://www.consultant.ru/ document/cons doc LAW 224600.

Протасеня 2017 - Протасеня Д.Н. Государственная поддержка развития кластера социально-ориентированных некоммерческих организаций в Российской Федерации // Государственное и муниципальное управление. Ученые записки СКАГС. 2017. № 1. С. 261-269.

Рудник, Куштанина, Романова 2017 - Рудник Б.Л., Куштанина Е.В., Романова В.В. Привлечение НКО к оказанию услуг социальной сферы // Вопросы государственного и муниципального управления. 2017. № 2. С. 105-129.

Самойлова 2018 - Самойлова А.Н. Оценка состояния и влияния некоммерческих организаций на развитие российской экономики // Juvenis scientia. 2018. № 9. C. 20-24.

Справится ли государство... 2012 - Справится ли государство в одиночку? О роли НКО в решении социальных проблем: Аналитический доклад НИУ ВШЭ / под ред. Л.И. Якобсона,
И.В. Мерсияновой. Изд. 2-е, перераб. и доп. М.: НИУ ВШЭ, 2012.

Суслова 2014 - Суслова С.В. Некоммерческие производители на региональных квазирынках социальных услуг // Вопросы государственного и муниципального управления. 2014. № 3. C. $72-89$.

Участие... 2019 - Участие НКО в оказании услуг в социальной сфере. Специальный доклад Общественной палаты Российской Федерации. М.: Современные информационные системы, 2019.

Шевченко, Захаров 2016 - Шевченко Н.В., Захаров В.M. Практика взаимодействия органов власти и некоммерческих организаций (на примере Белгородской области) // Ars Administrandi. 2016. № 4. C. 5-19.

Krasnopolskaya, Skokova, Pape 2015 Krasnopolskaya I., Skokova Yu., Pape U. Government-Nonprofi t Relations in Russia's Regions: An Exploratory Analysis // Voluntas. 2015. Vol. 26. P. 2238-2266.

Salamon, Benevolenski, Jakobson 2015 Salamon L.M., Benevolenski V.B., Jakobson L.I. Penetrating the Dual Realities of Government Nonprofit Relations in Russia // Voluntas: International Journal of Voluntary and Nonprofit Organizations. 2015. Vol. 26, № 6. P. 2178-2214.

\section{REFERENCES}

Artamonova A.S., 2018. The functioning of socially oriented non-profit organizations in Russian regions. Problems of Territory's Development, no. 5 (97), pp. 55-67.

Belokrylova O.S., Vakhtina M.A., 2017. Providing the equal rights of participants of the market of social services: problems and solutions. State and municipal administration. Proceedings of the North Caucasian Academy of Public Service, no. 1 , pp. $78-84$.

Boguslavskaya S.B., Bobrova O.S., 2016. Evaluation of the effectiveness of projects of non-profit organizations, social entrepreneurship and civil initiatives. Saint Petersburg, Polytechnical Institute.

Borisova E.I., Polishchuk L.I., 2009. Efficiency analysis in the non-profit sector: problems and solutions. Economic journal of the Higher school of Economics, no. 13 (1), pp. 80-100.

Volunteering and participation of Russians in the activities of NGOs and civil initiatives. Center for research of civil society and non-profit sector. URL: https://grans.hse.ru/06_04_2017 (accessed 23 September 2019). 
Gromova M.N., Mersiyanova I.V., 2016. State Support of the Non-profit Sector and Issue of Estimation of its Efficiency. Civil society in Russia and abroad, no. 1, pp. 39-44.

Report on the state of civil society in the Russian Federation for 2015. Moscow, Public chamber of the Russian Federation.

Road map "Support for access of non-governmental organizations to the provision of services in the social sphere". URL: http://economy.gov.ru/ minec/activity/sections/socorientnoncomorg/ 2016291104 (accessed 23 September 2019).

Zabolotnaya G.M., Larionov A.V., 2017. Regional Practices of Institutionalization of NonGovernmental Social Welfare Services' Providers. Public Administration Issues, no. 3, pp. 72-91.

Zemlyak S.V., Lapshova O.A., Shelomentseva M.V., 2016. Interaction of regional authorities with community non-profit organizations. Economics. Tallage. Right, no. 5, pp. 105-112.

Korneeva I.E., 2017. Market orientation in non-profit sector: the concept and main research directions. Vestnik of Saint Petersburg University. Management, no. 16, iss. 4, pp. 564-595.

Korneeva I.E., Oyner O.K., 2018. Market Orientation in Russian Non-Profit Organizations: Impact on the Performance. Vestnik of Saint Petersburg University. Management, no. 17 (4), pp. 437-464.

Kosygina K.E., 2017. Position of the non-profit sector in the regional economic system. Issues of territorial development, vol. 4 (39). URL: http:/ /vtr.isert-ran.ru/article/2360 (accessed 23 September 2019).

Kulkova V.Yu., 2019. Organization of infrastructure support for socially oriented non-profit organizations of the service sector in public administration of the Russian Federation. Management Issues, no. 2 (38), pp. 58-65.

Mersianova I.V., Benevolenski V.B., 2016. The Comparative Advantages of NPOs as Social Welfare Services Providers: an Examination in the Russian Context. Public Administration Issues, no. 4, pp. 7-26.

Mersianova I.V., Benevolenski V.B., 2017. NPOs as Social Services Providers: Organizational Weaknesses Verifying. Public Administration Issues, no. 2, pp. 83-104.

Moskovskaya A.A., 2018. Incentives and Barriers to Engaging Non-State Providers in the Provision of Public Social Services: Russian and Foreign Experience. Public Administration Issues, no. 3, pp. 88-116.

Nikolenko N.A., Serova Ya.I., 2017. Public sector and socially oriented nonprofit organizations in the sphere of social protection of population: partners or competitors? Bulletin of Udmurt University. Sociology. Political science. International relations, iss. 2, pp. 162-166.

Report on the implementation by the subjects of the Russian Federation of measures to ensure access of socially oriented non-profit organizations to the provision of services in the social sphere in 2018. URL: http:// nko.economy.gov.ru/portalnews/read/4967 (accessed 23 September 2019).

Mersiyanova I.V. (ed.)., 2018. Evaluation of economic and social efficiency of volunteer activity: methodological approaches and problems of implementation. Moscow, Higher school of Economics.

Palybina A.S., Pankova E.G., Solovyeva T.V., Bistyaikina D.A., 2017. Noncommercial organizations in the system of population's social service. Discussion, no. 10 (84), pp. 55-59.

Resolution of the government of the Volgograd region dated 26.03.2013 No. 128-p "On approval of the action plan ("road map") "Improving the efficiency and quality of services in the sphere of social services of the population of the Volgograd region for 2013-2018”. URL: http:/ /www.consultant.ru/law/review/reg/rlawc/ rlawc1262013 (accessed 23 September 2019).

Order of the Ministry of labor of Russia of 30.04.2014 $N 282$ (ed. of 13.04.2016) "On the action plan ("road map") "Improving the efficiency and quality of services in the field of social services (2013-2018)". URL: http://www.consultant.ru/ document/cons doc LAW 224600.

Protasenya D.N., 2017. Governmental support for the development of socially-oriented non-profit organizations cluster in the Russian Federation. State and municipal administration. Proceedings of the North Caucasian Academy of Public Service, no. 1, pp. 261-269.

Rudnik B.L., Kushtanina E.V., 2018. Involvement of NPOs in providing social sphere services. Public Administration Issues, no. 2, pp. 105-129.

Samoilova A.N., 2018. Estimation of non-profit organizations' state and their influence on development of the Russian economy. Juvenis scientia, no. 9 , pp. 20-24.

Yakobson L.I., Mersiyanova I.V., eds., 2012. Will the state cope alone? On the role of NGOs in solving social problems: Analytical report of the HSE. Moscow, HSE.

Suslova S.V., 2014. Nonprofit providers on regional social service qausi-market. Public Administration Issues, no. 3, pp. 72-89.

Participation of NGOs in the provision of services in the social sphere, 2019. Special report of the Public chamber of the Russian Federation. 
Public chamber of the Russian Federation. Moscow, Modern information systems.

Shevchenko N.V., Zakharov V.M., 2016. Features of interaction of authorities and non-profit organizations (exemplified by Belgorod region). Ars Administrandi, no. 4, pp. 5-19.

Krasnopolskaya I., Skokova Yu., Pape U., 2015. Government-Nonprofit Relations in Russia's
Regions: An Exploratory Analysis. Voluntas, vol. 26, pp. 2238-2266.

Salamon L.M., Benevolenski V.B., Jakobson L.I., 2015. Penetrating the Dual Realities of Government Nonprofit Relations in Russia. Voluntas: International Journal of Voluntary and Nonprofit Organizations, vol. 26, no. 6, pp. 21782214.

\section{Information About the Authors}

Mariya B. Poltavskaya, Candidate of Sciences (Sociology), Associate Professor of Department of Sociology and Social Technologies, Volgograd State University, Prosp. Universitetsky, 100, 400062 Volgograd, Russian Federation, poltavskaya@volsu.ru, https://orcid.org/0000-0001-7275-626X

Elena O. Danilova, Candidate of Sciences (Sociology), Senior lecturer, Department of Sociology and Social Technologies, Volgograd State University, Prosp. Universitetsky, 100, 400062 Volgograd, Russian Federation, danilovaelena@volsu.ru, https://orcid.org/0000-0002-2859-2226

Elena V. Abashkina, Candidate of Sciences (Sociology), Associate Professor, Department of Sociology and Social Technologies, Volgograd State University, Prosp. Universitetsky, 100, 400062 Volgograd, Russian Federation; Consultant of the Department of Information and Methodological Work, Committee of Social Protection of the Population of the Volgograd Region, Novorossiyskaya St., 41, 400087 Volgograd, Russian Federation, E_Abashkina@volganet.ru, https://orcid.org/0000-0002-6677-109X

\section{Информация об авторах}

Мария Борисовна Полтавская, кандидат социологических наук, доцент кафедры социологии и социальных технологий, Волгоградский государственный университет, просп. Университетский, 100, 400062 г. Волгоград, Российская Федерация, poltavskaya@volsu.ru, https://orcid.org/0000-0001-7275-626X

Елена Олеговна Данилова, кандидат социологических наук, старший преподаватель кафедры социологии и социальных технологий, Волгоградский государственный университет, просп. Университетский, 100, 400062 г. Волгоград, Российская Федерация, danilovaelena@volsu.ru, https://orcid.org/0000-0002-2859-2226

Елена Викторовна Абашкина, кандидат социологических наук, доцент кафедры социологии и социальных технологий, Волгоградский государственный университет, просп. Университетский, 100, 400062 г. Волгоград, Российская Федерация; консультант отдела информационно-методической работы, комитет социальной защиты населения Волгоградской области, ул. Новороссийская, 41, 400087 г. Волгоград, Российская Федерация, E_Abashkina@volganet.ru, https://orcid.org/0000-0002-6677-109X 